\title{
High Performance Liquid Chromatography (HPLC) Screening among Filipinos with Suspected Thalassemia
}

\author{
Terence Diane F. Fabella, ${ }^{1}$ Catherine Lynn T. Silao,,${ }^{1,2}$ Maria Liza T. Naranjo, ${ }^{3}$ \\ Carmencita D. Padilla ${ }^{1,2}$ and Ernesto DJ Yuson ${ }^{3}$ \\ ${ }^{1}$ Institute of Human Genetics, National Institutes of Health, University of the Philippines Manila \\ ${ }^{2}$ Department of Pediatrics, College of Medicine and Philippine General Hospital, University of the Philippines Manila \\ ${ }^{3}$ Lung Center of the Philippines, Quezon City
}

\begin{abstract}
Introduction. Thalassemias and hemoglobinopathies are autosomal-recessive red blood cell disorders affecting hemoglobin $(\mathrm{Hb})$ quantity and/or quality. Clinical manifestations vary from clinically asymptomatic to transfusion dependent individuals. These disorders are global in scope and is prevalent in Southeast Asia hence screening in the Philippines is very crucial for its prevention and control.
\end{abstract}

Objective. Our retrospective study aimed to determine the frequency of thalassemias and hemoglobinopathies in patients referred to the Molecular Genetics Unit, Institute of Human Genetics, National Institutes of Health, University of the Philippines, Manila for High Performance Liquid Chromatography (HPLC) screening.

Methods. Blood samples from patients $(n=622)$ sent by hematologists from different parts of the country from October 2008 to February 2015 were analyzed. Extracted whole blood samples from the subjects were anticoagulated with ethylenediaminetetraacetic acid (EDTA) and were analyzed using BIORAD VARIANT ${ }^{\text {TM }}$ HPLC Testing System and VARIANT ${ }^{\mathrm{TM}}$ Beta Thalassemia Short (BTS) Program kit for the detection of abnormalities in hemoglobin. Interpretation of results were based on the submitted mean corpuscular volume (MCV), mean corpuscular hemoglobin $(\mathrm{MCH})$ values, and $\mathrm{Hb}$ typing via $\mathrm{HPLC}$ of the patients.

Results. Approximately twenty-nine percent $(29.10 \%, \mathrm{n}=181)$ of subjects were presumptively identified with thalassemias and hemoglobinopathies by HPLC. Beta-thalassemia trait, $\mathrm{Hb}$ E trait, and beta-thalassemia/Hb E disease were detected in 65 (10.45\%), 14 (2.25\%), and 3 (0.48\%) subjects, respectively. While suspected alpha-thalassemia, presumably $\mathrm{Hb} \mathrm{H}$ disease, was found in 99 (15.92 \%) patients. Interestingly, seventy-two percent $(72.11 \%, \mathrm{n}=318)$ of the patients with normal $\mathrm{Hb}$ typing via HPLC have low MCV and $\mathrm{MCH}$ values.

Conclusion. Results of this study provide the spectrum and frequency of thalassemias and hemoglobinopathies in patients referred to our laboratory for HPLC analysis.

Key Words: thalassemia, hemoglobinopathies, high performance liquid chromatography, Filipino, red cell indices

\section{INTRODUCTION}

Corresponding author: Terence Diane F. Fabella, RCh, MSc Institute of Human Genetics

National Institutes of Health

University of the Philippines Manila

Pedro Gil St., Ermita, Manila 1000, Philippines

Email: tffabella@up.edu.ph
Thalassemias and hemoglobinopathies rank among the most common blood disorders in the world. ${ }^{1}$ The World Health Organization (WHO, 1989) reported that $7 \%$ of the world's population is a carrier of the disorders. ${ }^{2}$ Cases of thalassemias and hemoglobinopathies, and some of its interactions, are reported to be a major health problem. ${ }^{3,4}$ Moreover, these disorders are both prevalent and widely distributed across Africa, the Mediterranean region, the Middle East, the Indian subcontinent, China, and Southeast 
Asia, therefore screening programs in these areas are necessary for the prevention and control of the disorders. ${ }^{2,5}$

Thalassemias are groups of autosomal recessive inherited blood disorders characterized by quantitative decreased or absence of production of globin chains of the hemoglobin $(\mathrm{Hb})$ molecule. ${ }^{6}$ Patients with aberrations in the beta globin chain are beta thalassemics while those with abnormalities in the alpha globin chain are alpha thalassemics. ${ }^{6}$ Beta thalassemia is further classified as trait, intermedia and major whereas alpha thalassemia is categorized as carrier, trait, $\mathrm{Hb} \mathrm{H}$ disease and $\mathrm{Hb}$ Barts hydrops fetalis depending on the severity of the disease. ${ }^{6,7}$ Clinical manifestations of thalassemia disorders vary from clinically mild anemia with mild persistent microcytosis to severe life-threatening anemia that causes death even in utero. ${ }^{4}$ In contrast, hemoglobinopathies such as $\mathrm{Hb} \mathrm{C}, \mathrm{Hb} \mathrm{S}$, and $\mathrm{Hb} \mathrm{E}$, result in abnormalities in the globin chains affecting the structure of hemoglobin molecules within red blood cells $\mathrm{s}^{4,5}$ which also cause significant clinical manifestations in some cases. ${ }^{4}$

The presumptive diagnosis of thalassemias and hemoglobinopathies is important in the prevention and control of the disorder and is done through the assessment of erythrocyte morphology and indices particularly the mean corpuscular volume (MCV) and mean corpuscular hemoglobin $(\mathrm{MCH})$, detection of $\mathrm{Hb}$ variants and quantification of $\mathrm{Hb}$ levels, detection of $\mathrm{Hb} \mathrm{H}$ inclusion bodies $^{2}$ and genetic analysis. Specifically, the BHES protocol is used in the presumptive diagnosis of thalassemias where (B) stands for the assessment of blood film and blood count; $(\mathrm{H})$ for $\mathrm{Hb}$ subtyping by high performance liquid chromatography (HPLC); (E) for analysis of blood sample via electrophoresis, and (S) for stability analysis of samples via the $\mathrm{H}$-inclusion test and/or sickle cell solubility test. Ultimately, definitive diagnosis is done via genetic analysis. ${ }^{8}$

The Bio-Rad VARIANT ${ }^{\mathrm{TM}}$ HPLC (Bio-Rad Laboratories, California, USA) Testing System, an automated cation exchange HPLC instrument used together with The VARIANT ${ }^{\mathrm{TM}}$ Beta Thalassemia Short (BTS) Program (Bio-Rad Laboratories) is a sensitive and precise method that is capable of accurately quantifying $\mathrm{Hb} \mathrm{A}_{2}$ and $\mathrm{Hb}$ $\mathrm{F}$ concentrations within the validated reportable range of $1.0 \%$ to $13.0 \%$ and $1.0 \%$ to $40 \%$, respectively. It is capable of detecting hemoglobinopathies such as $\mathrm{Hb} \mathrm{E,} \mathrm{Hb} \mathrm{D,} \mathrm{Hb} \mathrm{S,}$ and $\mathrm{Hb} \mathrm{C}$. $^{4,910}$ The program was also reported to be useful in the qualitative diagnosis of common alpha-thalassemias such as $\mathrm{Hb} \mathrm{H}$, EA Barts, and EF Barts diseases. ${ }^{2}$ Furthermore, hemoglobin fraction analysis by cation exchange HPLC has the advantage of quantifying $\mathrm{Hb} \mathrm{F}$ and $\mathrm{Hb} \mathrm{A}_{2}$ along with hemoglobin variant in a single highly reproducible system. ${ }^{11}$

Cases of thalassemia and hemoglobinopathies were found to be particularly prevalent in tropical and subtropical countries. ${ }^{12}$ In Southeast Asia alone, the approximate number of affected births is 0.66 per $1,000 .{ }^{13}$ In the Philippines, there is lack of available data on the frequency of thalassemias and other hemoglobinopathies. Our study aimed to determine the frequency of these disorders in Filipino patients referred to our laboratory for HPLC analysis. The results gathered in this study will provide initial data on frequencies and spectrum of thalassemia and hemoglobinopathy cases screened in our laboratory. The result of this study will also guide and aid future studies, particularly in the application of HPLC in presumptive diagnosis of thalassemias and other hemoglobinopathies in the Philippines.

\section{METHODS}

Six hundred twenty-two (622) patients with available $\mathrm{MCV}$ and $\mathrm{MCH}$, values referred by hematologists from different parts of the country from October 2008 to February 2015, two years old and above, regardless of gender and ethnic origin, were included in this retrospective study. The subjects included were patients referred by hematologists as part of the work up for anemia and for confirmation of clinically suspected thalassemia or hemoglobinopathy. The study was approved for implementation by the Research Ethics Board of the University of the Philippines, Manila (UPMREB 2017-229-01).

Five (5) $\mathrm{ml}$ of whole blood in ethylenediaminetetraacetic acid (EDTA) tube was collected from the subjects and sent to the Molecular Genetics Laboratory, Institute of Human Genetics (IHG), National Institutes of Health (NIH), University of the Philippines, Manila (UPM) for HPLC analysis. The samples collected were prepared using the BTS Program kit according to the manufacturer's instruction and were loaded on the VARIANT ${ }^{\mathrm{TM}}$ HPLC Testing System. The testing system used the $3.0 \times 0.46 \mathrm{~cm}$ cation exchange cartridge and a dual wavelength filter photometer for separation and detection of the different hemoglobin variants. ${ }^{2}$ Results were reported as chromatograms with time vs absorbance parameters. Hemoglobin types were determined based on $\mathrm{Hb} \mathrm{A}_{2}$, A, F, S, C, H and Barts levels (Figure 1).

Interpretation of patients' results were either normal hemoglobin type or non-clinically significant thalassemia, normal hemoglobin type with low MCV and $\mathrm{MCH}$ values, beta-thalassemia trait, $\mathrm{Hb} \mathrm{E}$ trait, beta-thalassemia/ $\mathrm{Hb} \mathrm{E}$ disease and suspected $\mathrm{Hb} \mathrm{H}$ disease, and were based on the submitted $\mathrm{MCV}$ and $\mathrm{MCH}$ values and $\mathrm{Hb}$ types seen in the HPLC chromatograms of the subjects (Table 1).

\section{RESULTS}

\section{Demographic Profile}

A total of 622 patients referred from October 2008 to February 2015 were included in this retrospective analysis. The patients screened included 346 (55.63\%) females and $265(42.60 \%)$ males. Majority of the patients were from the ages 2 to 5 years old ( $\mathrm{n}=137,22.03 \%)$ followed by patients with ages 6 to 10 years old $(n=134,21.54 \%)$ and 31 to 40 


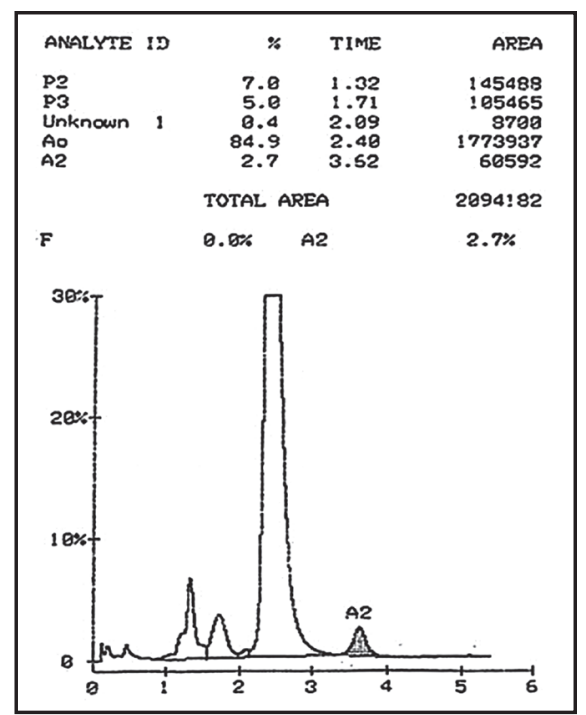

A

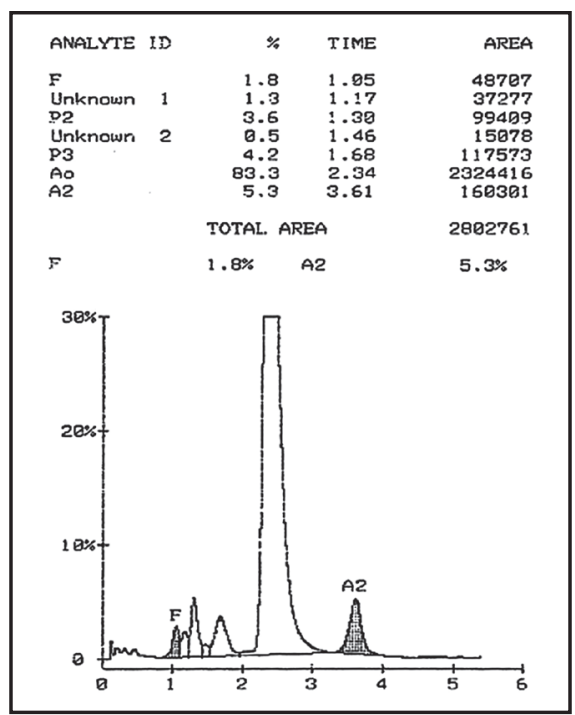

B

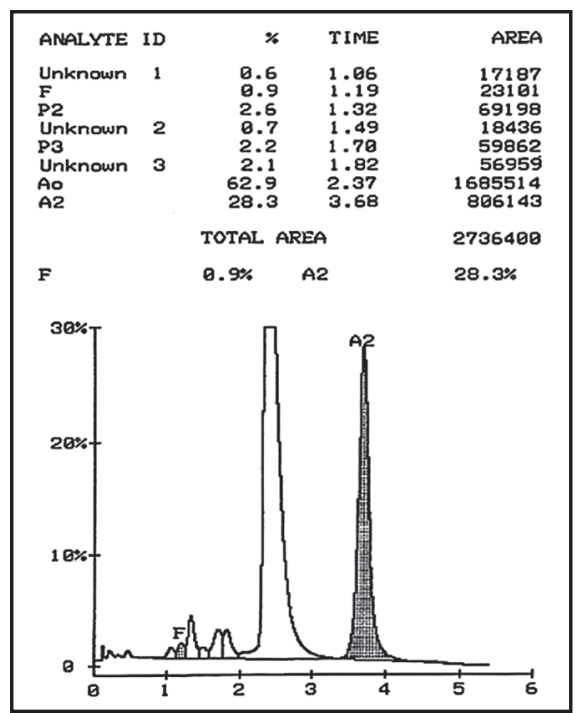

C
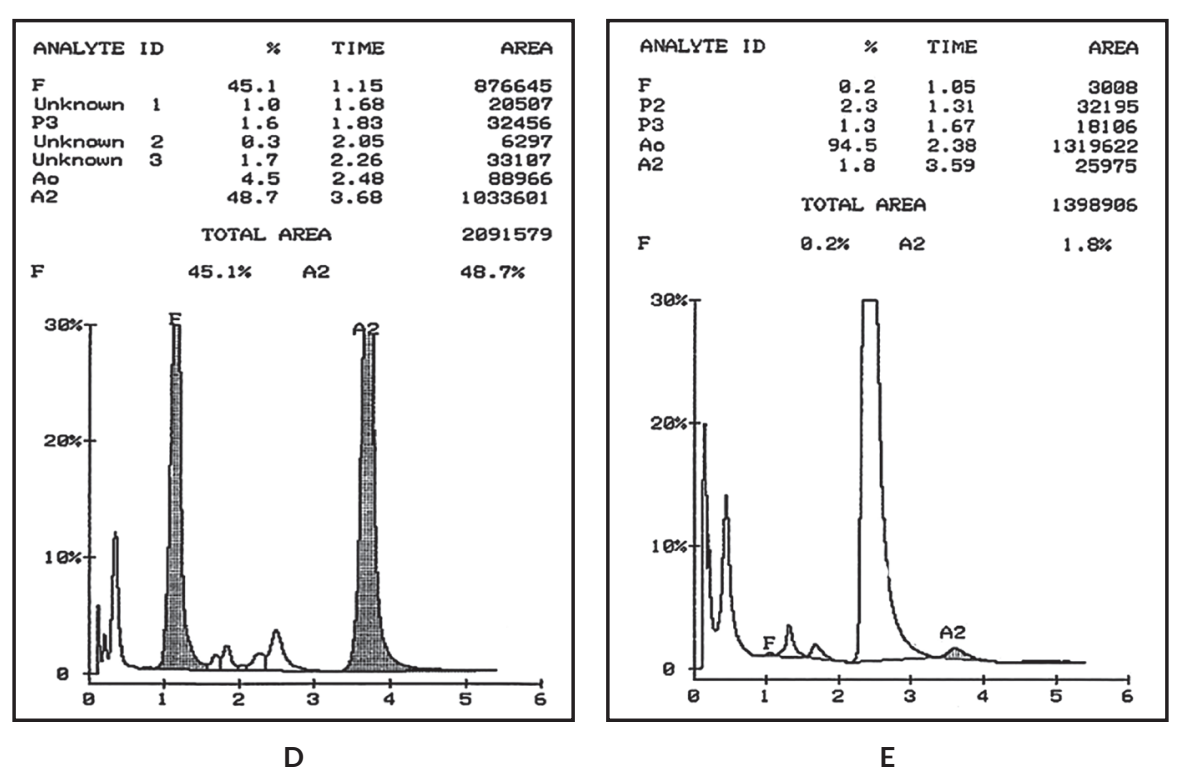

Figure 1. Hemoglobin typing via HPLC analysis. HPLC chromatograms of patients with hemoglobin type $(A) A_{2} A, H b A_{2} \leq 3.5 \%$ (B) $A_{2} A, H b$ A2 $3.6-8 \%$ (C) EA, Hb A $225 \%$ (D) EFA and (E) $A_{2} A$ Barts $H$ or $A_{2} A H$. X and $Y$ axes represent the retention time in minutes and percentage hemoglobin. Eluted peaks are $\mathrm{Hb}$ Barts and $H, F, A, A_{2}$ with retention times at less than 1 minute, $1.00-1.30,2.20-2.30,3.68$ - 3.98 minutes, respectively.

Table 1. Criteria used for presumptive screening of thalassemia

\begin{tabular}{|c|c|c|c|}
\hline MCV (fL) & $\mathrm{MCH}(\mathrm{pg})$ & Hb Type & Interpretation \\
\hline$\geq 80$ & $\geq 27$ & $\mathrm{~A}_{2} \mathrm{~A}, \mathrm{Hb} \mathrm{A} \leq 3.5 \%$ & Normal hemoglobin type or non-clinically significant thalassemia \\
\hline$<80$ & $<27$ & $\mathrm{~A}_{2} \mathrm{~A}, \mathrm{Hb} \mathrm{A} \leq 3.5 \%$ & Normal hemoglobin type with low levels of $\mathrm{MCV}(<80 \mathrm{fL})$ and $\mathrm{MCH}(<27 \mathrm{pg})$ \\
\hline$<80$ & $<27$ & $\mathrm{~A}_{2} \mathrm{~A}, \mathrm{Hb} \mathrm{A}_{2} 3.6-8 \%$ & Beta thalassemia trait with or without alpha thalassemia \\
\hline$<80$ & $<27$ & $\mathrm{~A}_{2} \mathrm{~F}$ & Beta thalassemia major with or without alpha thalassemia \\
\hline$<80$ or $\geq 80$ & $<27 \geq 27$ & $\mathrm{EA}, \mathrm{Hb} \mathrm{A} \geq 25 \%$ & Hb E trait \\
\hline$<80$ & $<27$ & $\mathrm{EE}, \mathrm{Hb} \mathrm{E} \geq 80 \%, \mathrm{Hb} F \leq 5 \%$ & $\mathrm{Hb} \mathrm{E}$ disease with or without alpha thalassemia \\
\hline$<80$ & $<27$ & EFA & Beta thalassemia/Hb E disease with or without alpha thalassemia \\
\hline$<80$ & $<27$ & $\mathrm{~A}_{2} \mathrm{~A}$ Barts $\mathrm{H}$ or $\mathrm{A}_{2} \mathrm{AH}$ & Suspected $\mathrm{Hb} \mathrm{H}$ disease \\
\hline
\end{tabular}


years old $(n=90,14.47 \%)$ (Table 2). Most patients were from Luzon ( $\mathrm{n}=361,58.04 \%)$, particularly Region II, the National Capital Region (NCR), Region IV-A and Region III (Table 3). Approximately five $(5.31 \%, \mathrm{n}=33)$ and two $(1.61 \%$, $\mathrm{n}=10)$ percent of the patients were referrals from Mindanao and the Visayas, respectively (Table 3 ).

\section{Frequency}

One hundred eighty-one ( $\mathrm{n}=181,29.10 \%)$ subjects referred to our laboratory presented with abnormal hemoglobin fractions on HPLC and were presumptively screened with thalassemias or hemoglobinopathies. Sixtyfive $(\mathrm{n}=65,10.45 \%)$ subjects were with the beta-thalassemia trait, fourteen $(\mathrm{n}=14,2.25 \%)$ with $\mathrm{Hb} \mathrm{E}$ trait, and three $(\mathrm{n}=3,0.48 \%)$ with Beta thalassemia/Hb E disease. Ninetynine $(n=99,15.92 \%)$ of the patients seen were suspected with $\mathrm{Hb} \mathrm{H}$ disease. Interestingly, approximately seventytwo percent $(72.11 \%, \mathrm{n}=318)$ of patients with normal hemoglobin type $(n=441)$ have low levels of $\mathrm{MCV}$ and $\mathrm{MCH}$ as seen in Table 4.

\section{DISCUSSION}

In the Philippines, this study is the first to report on the frequency data of thalassemias and hemoglobinopathies determined through the analysis of $\mathrm{MCV}$ and $\mathrm{MCH}$ values and $\mathrm{Hb}$ type of patients. This study determined that most of the patients referred to our laboratory for HPLC analysis were suspected $\mathrm{Hb} \mathrm{H}$ disease (15.92\%), beta thalassemia trait (10.45\%), $\mathrm{Hb} \mathrm{E}$ trait $(2.25 \%)$ and beta thalassemia/ $\mathrm{Hb}$ $\mathrm{E}$ disease $(0.48 \%)$ cases. Moreover, it is important to note that majority $(72.11 \%, n=318)$ of patients sent for testing with normal $\mathrm{Hb}$ type have low levels of $\mathrm{MCV}$ and $\mathrm{MCH}$.

The frequency of suspected $\mathrm{Hb} \mathrm{H}$ disease (15.92\%) reported in our study is higher than the reported gene frequency $(5 \%)$ of alpha thalassemia in the Philippines by Fucharoen et al. ${ }^{14}$ However, the number of $\mathrm{Hb} \mathrm{H}$ cases reported in this study might not be reflective of the true frequency of the disorder because though the HPLC method is considered a sensitive and accurate method for detecting normal and abnormal levels of hemoglobin, $\mathrm{Hb} \mathrm{H}$ and $\mathrm{Hb}$ Barts levels are only qualitatively analyzed using the HPLC method and the BTS Program. ${ }^{2}$ The evaluation via $\mathrm{H}$-inclusion test, peripheral blood film and confirmation via the molecular analysis are highly advised for these patients. On the other hand, the frequency of beta thalassemia trait $(10.45 \%, \mathrm{n}=65)$ reported in this study is comparable with the carrier frequency of beta thalassemia in Southeast Asia $(0-11 \%)$ reported by Weatherall et al. in $2001 .^{6}$ No beta thalassemia major was detected in the patients tested yet there were ten $(n=10,15.38 \%)$ beta thalassemia trait patients with increased $\mathrm{Hb} F$ values ranging from 5.10 to $11.10 \%$. The elevation of $\mathrm{Hb} \mathrm{F}$ of these patients could be due to co-inheritance of delta thalassemia or hereditary persistence of fetal hemoglobin (HPFH, OMIM \#141749).
Table 2. Age distribution of patients

\begin{tabular}{|ccc|}
\hline Age group & $\begin{array}{c}\text { No. of patients } \\
(\mathbf{n}=\mathbf{6 2 2})\end{array}$ & $\begin{array}{c}\text { Percentage } \\
(\%)\end{array}$ \\
\hline 2 to 5 years old & 137 & 22.03 \\
6 to 10 years old & 134 & 21.54 \\
11 to 20 years old & 89 & 14.31 \\
21 to 30 years old & 75 & 12.06 \\
31 to 40 years old & 90 & 14.47 \\
41 to 50 years old & 47 & 7.56 \\
51 to 60 years old & 24 & 3.86 \\
61 and above & 26 & 4.18 \\
\hline
\end{tabular}

Table 3. Distribution of patients based on region of origin

\begin{tabular}{lrr}
\multicolumn{1}{c}{ Region } & $\begin{array}{c}\text { No. of patients } \\
(\mathbf{n}=\mathbf{6 2 2})\end{array}$ & $\begin{array}{c}\text { Percentage } \\
(\%)\end{array}$ \\
\hline Luzon & & \\
NCR & 86 & 13.83 \\
CAR & 5 & 0.80 \\
Region I & 16 & 2.57 \\
Region II & 129 & 20.74 \\
Region III & 53 & 8.52 \\
Region IV-A & 57 & 9.16 \\
Region IV-B & 6 & 0.96 \\
Region V & 9 & 1.45 \\
& $\underline{361}$ & $\underline{58.04}$ \\
\hline Visayas & & \\
Region VI & 4 & 0.64 \\
Region VII & 5 & 0.80 \\
Region VIII & 1 & 0.16 \\
& 10 & $\underline{1.61}$ \\
\hline Mindanao & & \\
Region IX & 1 & 0.16 \\
Region X & 0 & 0 \\
Region XI & 19 & 3.05 \\
Region XII & 10 & 1.61 \\
Region XIII & 1 & 0.16 \\
ARMM & 2 & 0.32 \\
& $\underline{33}$ & $\underline{5.31}$ \\
\hline Data not available & 218 & 35.05 \\
\hline & &
\end{tabular}

Table 4. Age distribution of patients

\begin{tabular}{lcc}
\multicolumn{1}{c}{ Case } & $\begin{array}{c}\text { No. of patients } \\
\text { (n = 622) }\end{array}$ & $\begin{array}{c}\text { Percentage } \\
\text { (\%) }\end{array}$ \\
$\begin{array}{l}\text { Normal hemoglobin type or non- } \\
\text { clinically significant thalassemia }\end{array}$ & 123 & 19.77 \\
$\begin{array}{l}\text { Normal hemoglobin type with } \\
\text { low MCV and MCH values }\end{array}$ & 318 & 51.13 \\
$\begin{array}{l}\text { Beta thalassemia trait with or } \\
\text { without alpha thalassemia }\end{array}$ & 65 & 10.45 \\
$\begin{array}{l}\text { Beta thalassemia major with or } \\
\text { without alpha thalassemia }\end{array}$ & 0 & 0.00 \\
$\begin{array}{l}\text { Hb E trait } \\
\text { Hb E disease with or without } \\
\text { alpha thalassemia }\end{array}$ & 14 & 2.25 \\
$\begin{array}{l}\text { Beta thalassemia/Hb E disease } \\
\text { with or without alpha thalassemia }\end{array}$ & 0 & 0.00 \\
\begin{tabular}{l} 
Suspected Hb H disease \\
\hline
\end{tabular} & 3 & 0.48 \\
\hline
\end{tabular}


The presentation of $\mathrm{Hb} \mathrm{E}$ trait $(\mathrm{n}=14,2.25 \%)$ and the absence of $\mathrm{Hb} \mathrm{S}$ and $\mathrm{Hb} \mathrm{C}$ cases in the patients analyzed is consistent with literature. ${ }^{6} \mathrm{Hb} \mathrm{E}$ is the most common $\mathrm{Hb}$ variant reported in Southeast Asia with a carrier rate of more than $60 \%$. The detection of $\mathrm{Hb} \mathrm{E}$ in this study was via detection of $\mathrm{Hb} \mathrm{A}_{2}$ at $25.00 \%$ to $35.00 \%$ levels, ${ }^{2}$ since $\mathrm{Hb} \mathrm{E}$ co-elutes with $\mathrm{Hb} \mathrm{A}_{2}$, and this is comparable with the values detected in this study (25.00\% to $31.4 \%)$. Carrier frequency of $\mathrm{Hb} \mathrm{C}$ in the region was reported to be $0 \%$ while $\mathrm{Hb} \mathrm{S}$ was reported to be common in the Sub-Saharan Africa, the Indian subcontinent, and the Middle East only. ${ }^{6}$ Despite $\mathrm{Hb}$ $\mathrm{S}$ not being reported, the inclusion of sickle cell solubility tests in routine testing or screening for thalassemias and hemoglobinopathies is still recommended. The WHO recounted that inherited hemoglobin disorders including the sickle cell disorders are now common worldwide due to an increase in migration. ${ }^{13}$

The detection of beta thalassemia/ $\mathrm{Hb} \mathrm{E}$ disease in $0.48 \%(n=3)$ of the subjects in this study is important to note. Although $\mathrm{Hb} \mathrm{E}$ disease is benign, it is considered clinically important when co-inherited with beta-thalassemia because it results to a clinical condition similar to beta thalassemia intermedia and major. ${ }^{6,15,16}$ In 2011, Olivieri et al. even indicated that globally, about fifty percent of the most severe form of beta thalassemia that requires transfusion from birth is due to its co-inheritance with $\mathrm{Hb} \mathrm{E}$ disease. ${ }^{17}$

Finally, three hundred eighteen patients $(n=318$, $72.11 \%)$ with normal $\mathrm{Hb}$ type $(\mathrm{n}=441)$ were observed to have low $\mathrm{MCV}$ and $\mathrm{MCH}$ values. These patients are advised to have further analysis via electrophoresis on cellulose acetate to rule out beta thalassemia, $\mathrm{H}$-inclusion test to rule out alpha-thalassemia and serum ferritin to rule-out anemia due to iron deficiency. ${ }^{18}$ In Canada, carrier screening is done in women with low MCV (microcytosis) and low $\mathrm{MCH}$ (hypochromia) values in the presence of normal hemoglobin type. These group of women were advised to have an $\mathrm{H}$-inclusion test and were simultaneously tested for serum ferritin to rule out iron deficiency anemia. This is important to consider as couples who are carriers of thalassemias and hemoglobinopathies has a $25 \%$ chance of conceiving newborns with clinically significant disease such as $\mathrm{Hb} \mathrm{H}, \mathrm{Hb}$ Barts hydrops fetalis and beta thalassemia major. ${ }^{5}$ Moreover, about one percent $(1.13 \%, \mathrm{n}=5)$ of these samples also have elevated $\mathrm{Hb} F$, ranging from 6.3 to $34.8 \%$, despite normal $\mathrm{Hb} \mathrm{A}_{2}$. Two patients from this group have $\mathrm{Hb} \mathrm{F}$ values of $22.00 \%$ and $34.80 \%$ and marginal $\mathrm{Hb} \mathrm{A}_{2}$ levels of $3.30 \%$ and $3.40 \%$, respectively. Delta-thalassemia causes elevation of $\mathrm{Hb} \mathrm{F}$ and decrease of $\mathrm{Hb} \mathrm{A}_{2}$ levels of beta thalassemia trait, ${ }^{19}$ suggesting that these two patients could be delta-beta thalassemia cases. This should be emphasized, as co-inheritance of delta thalassemia may have obscured the detection of the beta thalassemia trait, thus, carrier screening for beta thalassemia is also advised for these patients.

\section{CONCLUSION}

A significant proportion of thalassemias and hemoglobinopathies were noted in Filipinos referred to our laboratory for HPLC screening. Results of this study provide spectrum and initial data on the frequency of these diverse groups of diseases in Filipino patients tested in our laboratory. This study also showed that Hb typing via HPLC with evaluation of $\mathrm{MCV}$ and $\mathrm{MCH}$ values is an effective tool in screening thalassemias and hemoglobinopathies. However, for comprehensive work-up of suspected patients, adherence to the BHES protocol and confirmatory testing via genetic analysis is highly recommended. The authors also suggest for the confirmation of the thalassemias and hemoglobinopathies identified as well as its possible cooccurrence with other thalassemias and hemoglobinopathies as it may affect patient's course of disease and prognosis.

\section{Acknowledgments}

This work was supported by the Institute of Human Genetics, National Institutes of Health, University of the Philippines, Manila. The authors extend their sincerest gratitude to Dr. Thongperm Munkongdee, Kahlil Izza Rama and Karen Hernandez-Ottlik.patients with $\mathrm{AD}$.

\section{Statement of Authorship}

All authors have approved the final version submitted.

\section{Author Disclosure}

All authors declared no conflicts of interest.

\section{Funding Source}

None.

\section{REFERENCES}

1. Chan AYY, So CC, Kwan Ma ES, Chan LC. A laboratory strategy for genotyping haemoglobin $\mathrm{H}$ disease in the Chinese. J Clin Pathol. 2007 Aug; 60(8):931-4.

2. Fucharoen S, Winichagoon P, Wisedpanichkij R, Sae-Ngow B, Sriphanich R, Oncoung W, et al, Prenatal and postnatal diagnoses of thalassemias and hemoglobinopathies by HPLC. Clin Chem. 1998 Apr; 44(4):740-8.

3. Colah RB, Surve R, Sawant P, D’Souza E, Italia K, Phanasgaonkar $\mathrm{S}$, et al. HPLC studies in hemoglobinopathies. Indian J Pediatr. 2007 Jul; 74(7):657-62.

4. Clarke GM, Higgins TN. Laboratory investigation of hemoglobinopathies and thalassemias: review and update. Clin Chem. 2000 Aug; 46(8 Pt 2):1284-90.

5. Langlois S, Ford J, Chitayat D. Carrier screening for thalassemia and hemoglobinopathies in Canada. J Obstet Gynaecol Can. 2008 Oct; 30(10):950-9.

6. Weatherall D, Akinyanju O, Fucharoen S, et al. Inherited Disorders of Hemoglobin. In: Jamison DT, Breman JG, Measham $\mathrm{AR}$, et al., editors. Disease Control Priorities in Developing Countries. 2nd edition. Washington (DC): The International Bank for Reconstruction and Development / The World Bank; 2006. Chapter 34. Available from: https://www.ncbi.nlm.nih.gov/books/ NBK11727/ Co-published by Oxford University Press, New York. 
7. Cao A, Galanello R. Beta-thalassemia. Genet Med. 2010 Feb; 12(2):61-76.

8. George E. Screening of thalassaemia carriers and its limitations. J Hematol Thrombo Dis. 2014; 2(2):e109. doi:10.4172/2329-8790. 1000e109

9. Sharma A, Marwah S, Buxi G, Yadav R. Hemoglobin E syndromes: emerging diagnostic challenge in North India. Indian J Hematol Blood Transfus. 2013 Mar; 29(1):21-5.

10. Tan GB, Aw TC, Dunstan RA, Lee SH. Evaluation of highperformance liquid chromatography for routine estimation of haemoglobins A2 and F. J Clin Pathol 1993 Sep; 46(9):852-6.

11. Joutovsky A, Hadzi-Nesic J, Nardi MA. HPLC retention time as a diagnostic tool for hemoglobin variants and hemoglobinopathies: a study of 60000 samples in a clinical diagnostic laboratory. Clin Chem. 2004 Oct; 50(10):1736-47.

12. Williams TN, Weatherall DJ. World distribution, population genetics, and health burden of the hemoglobinopathies. Cold Spring Harb Perspect Med. 2012 Sep; 2(9):a011692. doi:10.1101/ cshperspect.a011692.

13. Modell B, Darlison Ma. Global epidemiology of hemoglobin disorders and derived service indicators. Bull World Health Organ. 2008 Jun; 86(6):480-7.
14. Fucharoen S, Winichagoon P. Haemoglobinopathies in Southeast Asia. Indian J Med Res. 2011 Oct; 134(4):498-506.

15. Vichinsky E. Hemoglobin e syndromes. Hematology Am Soc Hematol Educ Program. 2007;79-83.

16. Olivieri NF. The Beta-thalassemias. N Engl J Med. 1999 Jul; 341(2): 99-109.

17. Olivieri NF, Pakbaz Z, Vichinsky E. Hb E/beta-thalassaemia: a common \& clinically diverse disorder. Indian J Med Res. 2011 Oct; 134(4):522-31.

18. Lin CK, Lee SH, Wang CC, Jiang ML, Hsu HC. 23. Alphathalassemic traits are common in the Taiwanese population: usefulness of a modified hemoglobin $\mathrm{H}$ preparation for prevalence studies. J Lab Clin Med. 1991 Dec;118(6):599-603.

19. Velasco-Rodríguez D, Alonso-Domínguez JM, Gonzalez-Fernández FA, Villarrubia J, Ropero P, Martínez-Nieto J, et al. $\delta \beta$-Thalassemia Trait: How Can We Discriminate It From $\beta$-Thalassemia Trait and Iron Deficiency Anemia? Am J Clin Pathol. 2014 Oct; 142(4): 567-73.

The Acta Medica Philippina is now accepting original scientific papers, review articles and case reports for its upcoming issues. Please follow the format for submission as indicated in the "Instructions to Authors" elsewhere in the journal. All papers received shall be properly acknowledged. For inquiries and submission of proposals, please email us at actamedicaphilippina.upm@up.edu.ph 